\title{
Eurozone Crisis and Its Solutions: Some Thoughts about Parallel Currency Regime
}

\author{
Antonin Rusek \\ Correspondence: Antonin Rusek, Department of Economics, Susquehanna University, Selinsgrove, PA 17870, \\ USA. Tel: 1-570-372-4182. E-mail: Rusek@susqu.edu
}

Received: July 3, 2012

Accepted: July 25, 2012

Online Published: September 3, 2012

doi:10.5539/ibr.v5n10p11

URL: http://dx.doi.org/10.5539/ibr.v5n10p11

\begin{abstract}
European crisis arrived at the crossroad. The preservation of the Eurozone in its current shape and scale implies economic changes which are increasingly resented by nations on the Mediterranean littoral - those most affected by the crisis. Alternative policies of monetary and fiscal expansion threaten the EU members north of Alps by both devastating inflation and, given their demographics, the social justice and wellbeing. However, the restructuring of the Eurozone implies short to medium term undesirable consequences. This paper suggests that the introduction of the parallel currency alongside the Euro in most affected counties may be a solution which preserves the current scope and scale of the Eurozone, mitigates the impact of "southern" adjustment and reduces the Eurozone-wide impact of needed financial restructuring.
\end{abstract}

Keywords: centralized monetary policy, decentralized fiscal policy and banking, parallel currency

\section{Introduction}

Current conventional thinking in Europe argues that there are only two solutions to the Eurozone crisis - a debt monetization, or an Eurobond. The first is illegal under the European law, the second is now illegal under the German constitutional law. Moreover, an increased body of thought inquires about the possibility of the Eurozone's restructuring - effectively implying that some countries leave the common currency entirely.

All these "solutions" face seemingly unsurmountable obstacles. A monetization of debts threatens the Northern Eurozone countries with what they would consider an inflationary Armageddon. Eurobond (or any form of the "joint and common" responsibility for the Eurozone's countries debt) is unacceptable to the northern countries taxpayers, well aware about their growing contingent liabilities for their own future pensions and healthcare. And, indeed, it is argued that if a country would leave the Euro entirely, the resulting shock to the integrated Eurozone's financial system would have a significant and protracted negative effect on all European economies.

One possibility, however, is seldom mentioned - that is, the possible introduction of a second currency in the most affected countries, to be used domestically alongside with the existing Euro (hence the term "parallel" or sometimes "dual” currency regime).

An introduction of the "dual" currency would facilitate a restoration of competitiveness (as defined in the euro denominated costs - i.e. the internal devaluation) while simultaneously mitigating the devastating impact of current "austerity" arrangements on employment, standards of living and the political stability. Moreover, it could mitigate fiscal stresses by generating some inflation tax revenue.

Indeed, for this to work a managed bankruptcy (i.e. the debt restructuring) in at least some of the countries introducing the dual currency regime might be necessary, reducing the present value of the Euro denominated liabilities to a serviceable level. That would undoubtedly affect the creditors (Northern financial institution) but to a lesser and more manageable degree (if done properly, in a cooperative manner) compared to the case of the country outright leaving the Euro.

Existing discussions and ideas with respect to parallel and dual currency regimes are reviewed in the Part 2. Parts 3,4 and 5 then constitutes the analysis of the parallel currency idea as it may apply to current Eurozone circumstances. Part 6 concludes.

\section{Parallel Currency in History and the Economic Thought}

Parallel currency regime can be defined in general as the situation where two or more currencies (or currency proxies), including monetary metals, circulate simultaneously and fulfill one or more money functions in a single legal jurisdiction (a state or a group of states). 
Parallel currency regimes in the form of bimetallism (or multimetallism, as was more often the case) dominated the world markets and economies for the most of human history, effectively till the last third of the $19^{\text {th }}$ century. Several metals (and their combinations) were simultaneously used for coinage and as a medium of exchange, store of value and often the standards of deferred payments (or letters of credit for the long distance trade as the case might be). The gold and silver dominated in this regime, with copper coinage extensively used for local transactions and other needs.

The causes for these "parallel currencies" regimes varied by countries and regions. But in general a (hypothetical) "monometall" regime would fail to provide a desired quantity of payments specie (i.e. the liquidity), both for long distance exchanges (where both the gold and silver were used) and local markets (where the copper coinage dominated). Problems in this system stemmed from the changing relative market values of the underlying monetary metals. But the lack of viable alternatives maintained these regimes till the onset of the modern economy and often beyond. For the more detailed and penetrating discussion the interested reader should consult, for example, Davies (2003), or Redish (2006).

The developments in techniques of government, accounting, banking and credit management, together with a seemingly steady growth in the gold supply and advancements in printing technologies resulted in the basically worldwide adoption of the monometallic, "gold" standard monetary regime in the last third of $19^{\text {th }}$ century. The important, even if often overlooked characteristic of this regime is a widespread and expanding use of paper banknotes and transferable bank balances in lieu of a direct use of the monetary metal (gold) for all monetary functions. However, in a gold standard regime these banknotes are redeemable for the gold in predetermined ratios - which limits their issuance and (supposedly) ensures the monetary stability. Banknotes here are simply more efficient and convenient to use compared to gold coins and bars.

Gold standard, by tying the money supply to the supply of gold proved to be too restrictive in the age of the full employment and the growth oriented economic policies, especially when those policies were coupled with the efforts to engineer the social and income redistribution reforms. Hence, it was eventually abandoned in favor of single fiat currency regimes on the nation state basis. The disappearance of any outside constraints on the money creation proved to be too tempting for some governments, who found in a rapid monetary expansion an easy answer to the contradictions and problems of domestic economic and social policies. The results were protracted inflationary waves (especially in South America, but in Israel, Turkey and some other countries as well) in 1970s, 1980s and 1990s. In this environment the fiat paper currency in the affected countries rapidly became rather undesirable, especially in its functions as the store of value and the standard of deferred payments.

As a response, the population in affected countries resolved (gradually) to the use of foreign currencies as price standards, stores of values and the standard of deferred payments, even if the domestic currency (to a degree) preserved its role as means of exchange, but often using the "grey" or black markets exchange rates. What developed was a "dual" or "parallel” currency regime (albeit often of a doubtful formal legality), known as the "dollarization" - i.e. the US dollar being used simultaneously with the domestic currency in several monetary functions in a single country. The thorough survey of this process together with a penetrating theoretical analysis can be found in Agenor (1992).

The advent of globalization, which, among other things, forced domestic political, economic and monetary reforms, halted the dollarization "experiments", even if in many countries the phenomenon itself was never really reversed.

Besides those major episodes of parallel currency regimes in the world economic history, one may mention some more limited, local episodes. Most known is probably the so called Woergl Experiment. The Tyrolean town of Woergl issued local "labor certificates" which were used to pay local laborers wages and could be exchanged for local goods in local stores. The experiment lasted in 1932 and 1933 and is credited with a successful mitigation of a catastrophic impact of the great depression on the town of Woergl and its vicinity. (For details, see Litaer, 2002.) It is interesting to point out that the "Woergl Experiment" addressed the shortage of liquidity in the local economy in the gold standard regime. Experiment was concluded when the gold standard in Austria was abandoned and the liquidity in the "official" paper currency was restored. Several similar experiments in a recent Greece experience are described in Sotiropoulou (2010).

On the pure theory side, the feasibility of a parallel currency regime was investigated by Camera, Craig and Waller (2003). Being purely theoretical, their model is only a highly stylized reflection of a very simple economy. Nevertheless, they show the existence of a stable equilibrium where two distinct currencies will be used simultaneously and their exchange rate will be market determined. 
In the context of a current Eurozone problems the discussion of the possible parallel currency regime solution(s) is (somewhat surprisingly) rather meager. A parallel currency regime as the solution to the Eurozone's problems was suggested by Goodhart and Tsomocos (2010), and Butler (2011). The legal aspects of the problem were discussed by Thieffry (2011). Some of the ideas expressed by those authors will be discussed in the next part. However, at the time of this writing (July 2012), the author is not aware of any published academic or policy study addressing the possibility of a parallel currency regime as the possible answer to Eurozone's problems.

\section{Eurozone's Problem - Could Parallel Currency Regime Help?}

To answer the question in the subtitle above, it is necessary to specify what is the nature of the "Eurozone Problem". For many this answer is simple enough - the unsustainable fiscal stands of some Eurozone member countries, which resulted in the so called European sovereign debt crisis. This situation is supposedly the consequence of the fiscal autonomy of individual member states. This fiscal autonomy prevents a centralized "European" fiscal solutions. The answer to the question in the subtitle is then the Eurozone fiscal centralization so called Economic Government for Europe, which would enforce fiscal policy rules continent-wide. Parallel currency regime is obviously irrelevant here.

However, this answer is simplistic, reflecting more desires of elites for more "paneuropeanism" than the reality of the European political social and economic landscape. After all, both EU and especially the Eurozone are primarily political creations, albeit couched and exercised in mostly economic terms (Weigel, 2008). To define the Eurozone problems realistically, we have to connect the economic and political realities. Pragmatism, not dogmatism is called for.

\subsection{Eurozone's Problems}

In general terms, Eurozone's economic problems can be traced to the dynamic instability caused by the arrangement where the monetary policy is centralized (single currency controlled by a single central bank ECB), whereas the fiscal policy and the financial control and supervision of the private sector remains the domain of individual states. The Eurozone's establishment intended to deal with this issue by creating the Stability and Growth Pact (SGP) which attempted to restrict the general fiscal policy rules and positions (by specifying the maximum permissible deficits and public debts) compatible with the goals of the monetary policy and the common currency stability. The national autonomy in the financial and regulatory areas was to be coordinated by generally agreed EU directives.

Indeed, such an arrangement was (and is) unwieldy. It necessarily had to rely on the willingness (and the ability) of national governments to put the requirements of a common currency stable functioning over and above of whatever national requirements (and political exigencies) may be. (Indeed, SGP was "restructured" and in fact softened in 2005 when Germany and France were unwilling to put the interest of the common currency - and hence a progressive integration - ahead of domestic political "conditions". Perhaps that is where the roots the current crisis lie?)

It is easy to criticize those arrangements, as many economists and European integrationist do. But one must always keep in mind that the EU and the Eurozone are, first and foremost, political creations and as such their "organization" is limited by what is politically possible. It should be always stressed that both the EU and the Eurozone are the result of intergovernmental treaties and therefore lack a direct democratic political legitimacy. The latter remains vested in national governments of individual member states. And they are those states who transfer parts of their executive and political powers to the EU and the Eurozone as the consequence of this legitimacy. The extend of those transfers is determined by the Maastrich and Lisbon treaties and, for all practical purposes, constitutes the maximum of governing powers the democratically legitimate national governments are willing to concede to the EU and the Eurozone.

(One should remark here that, indeed, there are attempts - some even successful - to circumvent the legal structure of the EU and Eurozone treaties. The disregard for the "no bailout" rule is the glaring example. But this sneaking EU and Eurozone centralization, conducted under the excuse of an "economic emergency" has its limits. After all, the more centralized EU was rejected by the French and Dutch referenda regarding the so called "EU constitution" in 2005. And there is no political appetite to return to this "idea" today.)

The current economic policy and decision making arrangements in the EU and the Eurozone may be inefficient in the view of many economists and Europeanist elites, but it is the maximum which is politically possible. Attempts to go beyond these arrangements for the sake of preserving the present common currency arrangements threaten to unravel the basis of the postwar European developments and prosperity.

Specifically, the recent discussion identified three areas where the Eurozone problems manifest themselves: 
i) "Sovereign Debt” issues (sustainability and financiability) in some ("southern tier”) countries

ii) Competitiveness problems in the same ("southern tier") countries

iii) Instability and undercapitalization of the banking sector Eurozone-wide

All three are indeed interdependent. Their genesis and the role the establishment of the common currency area played in their development were discussed elsewhere (Matthes, 2009; DeGrauwe, 2011) and will be not repeated here. However, we will address the dilemmas posed by the proposed solutions.

\subsection{Proposed Solutions to Eurozone Problems}

In general there are two solutions suggested for the Eurozone problems. One, as hinted above, and which command the majority of economists and European elites opinions, is the fast progress toward the centralization of economic decision making in the Eurozone, That is where the intellectual underpinnings for concepts of "EU economic government", “Common EU (or the Eurozone) finance minister", and so called "Eurobonds" come from. Alternatively, some people suggest a dissolution or a territorial reconstruction of the Eurozone.

The centralization of the economic decision making in the Eurozone would indeed solve the problems, assuming that the newly created "economic" government would make reasonable decisions (a very strong assumption indeed).

The centerpiece of this idea is the creation of some kind of a central fund, guaranteed jointly and indivisibly by all Eurozone countries, which would finance, at presumably low interest rates, the member countries fiscal deficits (or parts thereof).

If designed properly, such a fund could mitigate the public financing pressure on some states, providing either loans or guaranties to loans at lower than market interest rates. However, to provide a dynamic stability some stable predictability of the future fiscal dynamics is required - otherwise the proposed fund would be just a maelstrom sucking in the fiscally healthy countries eventually. That implies a commitment to the future fiscal discipline from the Eurozone member countries. And the experience with SGP teaches everybody that the more than an international treaty with a meager enforcement mechanism is needed. Hence the talk about the need for revisions of "European treaties", aimed at the establishing the EU "tzar" with the power to adjust national budgets over the heads of national governments in a case the latter deviate from the agreed upon path. Applauded by Europeanist elites, such an arrangement would effectively reduce the European countries to the position of American states. 200 plus years of European history and national emancipation would be thrown away.

Perhaps more importantly, a stability of the centralized fiscal stance would require a convergence of tax systems, spending patterns and (implicitly but nevertheless) the reforms and convergences of labor market structures, pensions and healthcare arrangements. Given the rate of the "progress" in those areas in the last almost 20 years (from the Maastricht treaty establishing the European Union) one may assume that required changes are beyond the existing political realities.

But without the establishment of the political structure democratically accepted by the all participating countries, the fiscal (i.e. the economic) government of the Eurozone is an illusion. Or worse, it is the mechanism to transfer resources from the North to South, with no guarantee of the future stable dynamics (that is the meaning of the German term "transferunion”).

(One cannot escape the impression that the actually proposed solutions to the Eurozone problems all operate on the hope that the world - and especially American - economy will restore its dynamic growth starting from 2012. If realistic, this would improve the Eurozone growth and automatically mitigate the fiscal pressures. The proposed "centralist" solutions are then designed to "calm down" the markets and hence to reduce the risks of a financial collapse in some countries till the renewed growth "takes care" of the problem. If this is the idea then the political unfeasibility of proposed "centralist" solutions is irrelevant. It will never need to be actually implemented. Well, this is what one European writer (Wolfgang Munchau) calls "kicking the can down the road, but filling it with a high explosive first. American term is "hopium".)

The creation of a centralized fund to help recapitalize European banks is a good, long overdue idea - for the future. (US FDIC structure could serve as a guide). Indeed, the common currency and the transeuropean banking sector do justify the common and centralized regulatory, supervision and bank insurance agency. However, very little progress was achieved in this area from 1999, mostly for political reasons. (Individual Eurozone states consider the bank regulation, supervision and insurance to be the national, not a "Common European" area.) 
Moreover, even if a centralized solution is achieved for the future (with real powers), that does not solve the current problem.

A bank recapitalization on the individual, state by state basis would just exacerbate a sovereign debt problem on the Mediterranean littoral (here the Ireland's situation may serve as the both example and warning). A transeuropean solution would then require fiscal transfers of a magnitude hardly politically acceptable to the northern "donor" countries.

Finally, the fiscal centralization, i.e. the creation of the "economic government", would do very little (certainly in the short to medium term) for what some consider the Eurozone's dominant problem: the protracted and increasing lack of competitiveness in some countries, especially on the Mediterranean littoral (Greenspan, 2011; Hans-Werner Sinn, 2011).

Indeed, the protracted austerity (i.e. the economic growth below the EU and the world rates) would eventually bring inflation and perhaps wages in the Mediterranean littoral countries below the Eurozone average, reversing the existing $25-35 \%$ of the real appreciation compared to Germany. However, the appreciation process took 10 years and the real depreciation is unlikely to happen faster, to say nothing about the domestic political sustainability. The deep and radical changes in labor markets would accelerate the process, but again, who will introduce and enforce those? The required degree of the political and economic centralization in the Eurozone is not politically feasible today.

The converse of this situation, i.e. the protracted inflationary wave in northern countries leading to a real appreciation there is equally politically impossible. Nobody in his right mind would expect the public of northern Eurozone countries to accept the protracted inflationary Armaggedon.

To summarize at this point, the institution of the real Eurozone economic government, which would centralize the most of important economic policy functions and hence created an environment conducive to the solution of the Eurozone crisis and the long term stabilization of the single currency, is politically extremely unlikely. But without such a solution the European crisis will simmer and perhaps accelerate. Where to? Nobody knows, but the thought about the either collapse or a substantial restructuring of the Eurozone itself gained the currency and attention recently.

The problem indeed is that nobody has an idea what either the collapse or a substantial restructuring of the Eurozone would entail. The problem is the financial sector integration in Europe - curiously enough the one desired result of the common currency regime (assuming indeed that this regime is sustainable). Setting aside the legal considerations (undoubtedly important, but beyond the scope of this analysis), disentangling the complex web of Euro denominated financial assets and liabilities connecting together Eurozone agents across national boundaries is considered a daunting if not impossible task. And one sided solutions would certainly inflict significant and probably cascading losses (even if the apocalyptic estimates of some institutions like USB and HSBC should be dismissed of hand as probably the crack induced fantasies). But anyway, the collapse or even a substantial reconstruction of the Eurozone today is undesirable and should be avoided if possible.

Indeed, Eurozone is in the situation where a possible economic solution is not politically viable. This then makes the Eurozone's collapse (or a substantial restructuring) more likely. The fear of this event then pushes Eurocrats toward "solutions" which exacerbate not only Eurozone's difficulties, but increasingly pose threats to the overall architecture of the EU itself.

Nevertheless the question remains: Given the constraints elucidated the discussion above, is it possible to find a compromise solution which would at least interrupt the relentless march toward the collapse?

\section{The Parallel Currency Idea}

The parallel currency regime simply means that a country (the Eurozone member) introduces the second currency (SC for short). On this state territory the second currency will be available to perform the same functions as the existing currency (the Euro), subject to regulations elaborated below. The use of this currency will be illegal outside the country which issued it and in all contracts involving the non-residents.

The SC will be provided only to citizens and legal residents of the issuing country. The use of such a currency by anybody else will be strictly illegal anywhere, including the territory of the issuing country. The relationship between SC and Euro (the exchange rate) will be determined by the markets.

On the technical side, the SC could be introduced by legislating that a predetermined share of the domestic government expenditures will be in SC, the rest in Euro. The same ratio should be applied to the redenomination of domestic debt being held by domestic entities. Simultaneously, all domestic contracts (both private and public 
contracts where both parties are domestic entities) will have a defined minimum share to be serviced in SC and the minimum share to be serviced in Euro. (Those minimum shares should not sum up to $100 \%$, creating a space for private re-contracting.) Finally, the tax liabilities should be determined in both Euro and SC such that the tax liabilities in Euro are sufficient to cover newly defined Euro based government expenditures and the required servicing of the domestic public debt in hands of foreign entities.

All contracts involving foreigners should be denominated and exercised in Euros. Financial sector should offer deposits and loans in both Euro and SC, subject to restrictions elucidated above.

On the policy side, a hard constraint (a constitutional amendment?!) should impose a balanced gross public accounts (including a debt service to nonresident entities) in Euros. A public accounts denominated in SC (both revenues and expenditure sides) should remain at the discretion of the country's government. The basic purpose of the parallel currency regime (i.e. the introduction of the SC) is to eliminate the need for new Euro borrowings together with the creation of an environment conducive to servicing the existing Euro denominated claims. Hence the balanced budget law elucidated above.

But the second purpose of introducing SC is to mitigate the negative (and at least in the Greek case obviously counterproductive) impact of the domestic austerity and the "internal devaluation" on both the economic performance and increasingly the social and political stability of the SC issuing country. Replacing the reduced and subsequently restricted Euro expenditures with SC expenditures, the euro accounts balance can be obtained at lower social and political costs.

Moreover, as long as SC accounts are unbalanced (presumably in deficit, otherwise the parallel currency exercise would be pointless) they must be financed by money (SC) creation, triggering the inflation in SC denominated prices. This should then lead to an increased private demand for the Euro as an inflation hedge, leading to the SC depreciation relative to Euro. This should facilitate the reduction of the domestic "average" unit labor costs. (Average in the sense of combining the Euro denominated labor compensation with the SC denominated labor compensation, the latter expressed in Euros using (the presumably depreciated) SC exchange rate.)

Resulting restoration in competitiveness (a real depreciation based on the ULC) should then improve a current account position, hopefully generating a surplus. This could be used to service the country's existing Euro based commitments.

Through this process an introduction of the parallel currency regime simultaneously improves the issuing country competitiveness (a problem ii) in part IIb above, which is not addressed by a centralization of Eurozone wide decisionmaking) and preserves the use of the Euro in the affected country.

As far as the "sovereign debt" issue is concerned, the parallel currency regime as discussed above preserves all "outside" liabilities in their euro denominations (i.e. no forced re-denomination - full or partial - here). The design of the parallel currency regime, with its commitment to the gross budgetary balance - i.e. the one which includes the "foreign" euro debt servicing in full - should, in principle, answer the "sovereign debt" concerns. This could be enhanced by stipulating that the "foreign" euro debt service enjoys the "seniority" status as far as the euro based budget expenditures are concerned. The logic here is that the "domestic" euro based expenditures can be substituted for by SC expenditures if needed, but foreign cannot.

In a case of some countries (Greece? Portugal?), the dynamic sustainability of this arrangement could be enhanced by the ex ante (that is, before the establishment of the parallel currency regime) public debt restructuring. But, obviously, the details will depend on the actual situation and timing.

It is useful to point out that if handled properly, the parallel currency regime(s) establishes the kernel of the "sovereign debt crisis" solvability based on the existing (or, perhaps, only slightly altered) degree of fiscal and economic decision making autonomy. No politically unpalatable degree of economic centralization is required.

Finally, the issue of the bank recapitalization. Obviously, the country introducing the parallel currency regime would recapitalize the domestic banking sector in the new SC. The design of the parallel currency regime as elaborated above (the "foreign" debt holdings issue) would by itself lessen the "additional capital" need of foreign banks.

In this context, it is important to compare the costs of bank recapitalization under the parallel currency regime to the alternatives. Available estimates indicate that the recapitalization costs under the current situation (either centralized or autonomous - i.e. country by country - solutions) would exceed the parallel currency regime for the simple reason of a persistent uncertainty about the debt service capacity and willingness of crisis countries to honor their obligations. 
And, indeed, the costs of leaving the Eurozone entirely (and hence the needs for bank recapitalizations under this scenario) are at this point basically uncalculable. But given the collapse of the cross border debt servicing under the Euro exit and/or Eurozone restructuring scenario, the bank recapitalization costs would exceed the same when debt servicing is preserved - i.e. the parallel currency regime(s).

The discussion up to this point indicates that a parallel currency regime in some countries could be a feasible way out from the ongoing eurozone crisis. But if it is so, why is it essentially ignored?

\section{Cons of the Parallel Currency Idea}

Objections and criticism of the above elucidated parallel currency regime idea can be expressed in the four different areas.

First, many would consider the above suggested regime unwieldy, too complicated and open to massive malfeasance. The actual system is unlikely to be the incentives compatible and as a such may invite a significant cheating and evasion. That relates especially to the "balanced Euro budget" provision and the restrictions limiting the use of the SC to domestic residents only. In addition some may consider the complexity of the system to be beyond the capacity of at least some governments to implement.

This criticism may certainly be valid, but we will never know unless we try. But to limit the negative possibilities, perhaps some EU wide cooperative arrangement would help to enforce the parallel currency rule and restrictions, especially as far as non-citizens and non-residents are concerned (both individuals and firms).

Second important objection relates to the legality of the parallel currency regime in the Eurozone member state. The current EU law, rooted in Maastricht and Lisbon treaties, simply does not even contemplate a parallel currency possibility, making its introduction in any single country in all probability illegal. However, the speed and frequency with which both the EU as a whole and the ECB ignored the legal restriction imposed on them by communities treaties makes this objection to sound hollow at best. And, indeed, one can imagine a quick approval for the alteration of basic treaties which would preserve the fiscal and economic policy autonomy and simultaneously address - and significantly alleviate - the "sovereign debt" crisis.

The third area of "resistance and resentment" to the establishment of the parallel currency regime(s) is the fear that such a regime would be the first step toward a country leaving and the Eurozone (eventually) disintegrating. That is certainly possible, but whether it is realistic depends on the actual design of the parallel currency regime. In the type of the system elaborated above, where all "international" euro-based commitments are preserved and so is the Euro for a part of domestic transactions and contracting, leaving the Euro would be equally traumatic and only slightly less costly under parallel currency regime as it would be today.

After all, the purpose of the parallel currency regime as suggested here is to preserve the use of the Euro (albeit with some limitations) and the scale and the scope of the Eurozone in the face of the increasingly hostile and threatening environment.

The last area of objections is purely political in nature, but it has to be mentioned. Some individuals hope that a current crisis will lead to a "more Europe". The current crisis appears to them as an excellent opportunity for the accelerated economic and fiscal "integration" - removing the powers of economic and fiscal policies from national governments and centralizing them on the union level, under the control of "enlightened" Europeanist elites. The solution of the current Euro crisis which would essentially preserve the current political arrangements is, indeed, undesirable for those individuals.

\section{In Lieu of Conclusion}

The analysis indicates that the properly structured parallel currency regime could provide a solution to the current Eurozone problems. Indeed, as any realistically conceivable solution it is not "optimal" in the purely economic sense. But its greatest strength is that it preserves the current reality of the fiscal and economic decision-making decentralization. After all, the Eurozone is the political arrangement, albeit the one stated basically in economic terms. If the Euro is to be preserved its political base is necessary. Anything else is a fantasy - but the fantasy with possibly extremely dangerous consequences. Europeans should remember their history.

\section{References}

Agenor, P.-R. (1992). Parallel Currency Markets In Developing Countries. Essays In International Finance, No. 188, November. Dept. of Economics, Princeton University, Princeton, NJ.

Butler, M. (2011, January 10). Parallel Currencies Could Boost Euro. Financial Times. 
Camera, G., Craig, B., \& Waller, C. J. (2003). Currency Competition in a Fundamental Model of Money. Working Paper \#03/11, Cleveland, OH: Federal Reserve Bank of Cleveland.

Davies, G. (2003). History of Money: From Ancient Times to the Present Day. Cardiff, UK: University of Wales Press.

De Grauwe, P. (2010). The Financial Crisis and the Future of the Eurozone. Breughels European Economic Policy Briefings, $n .21$.

De Grauwe, P. (2011). Managing a Fragile Eurozone. CESifo Forum, 12(2), 40-45.

Goodhart, C., \& Tsomocos, D. (2010, January 24). The Californian Solution For The Club Med. Financial Times.

Greenspan, A. (2011, October 6). Europe Crisis Is All About North - South Split. Financial Times.

Lietaer, B. (2002) The Future Of Money. New York, NY: Random House.

Matthes, J. (2009). Ten Years of EMU - Reality Test for the OCA Endogeneity Hypothesis, Economic Divergences and Future Challenges. Intereconomics, March/April, 114-128. http://dx.doi.org/10.1007/s10272-009-0285-z

Redish, A. (2006). Bimetallism: An Economic And Historical Analysis. Cambridge, UK: Cambridge University Press.

Sinn, H.-W. (2011, October 3). How to rescue the Euro: Ten Commandments. VoxEU.

Sotiropoulou, I. (2010). Exchange networks \& parallel currencies: Theoretical issues or research in Wonderland. $1^{\text {st }}$ International Conference in Political Economy, Rethymno, Greece, September.

Thieffry, G. (2011). Thinking the Probable: The Break-up of Monetary, Union. Journal of International Banking Law and Regulation, 3, 103-104.

Waigel, T. (2008). Introductory Statement for the Panel Discussion on the Occasion of The Forum: 10 Years of The European Economic and Monetary Union. In Economic and Monetary Union: 10 Years On, DG ECOFIN, Brusseles, Belgium, May. 